\title{
La memoria, la bistoria, el olvido: 10 años después, París, 2010
}

«...los primeros recuerdos encontrados en el camino son recuerdos compartidos...

Nos permiten afirmar 'que, en realidad, no estamos nunca solos'...»

MHO, p. 158.

Con motivo de los 10 años de la publicación de «La mémoire, l'histoire, l'oubli» de Paul Ricoeur (en adelante $\mathrm{MHO}$ ) se realizó el Coloquio «La memoria, la historia, el olvido: 10 años después» (Colloque La mémoire, l'bistoire, l'oubli: 10 ans après). Este evento se llevó a cabo en París en diciembre de 2010 bajo el patrocinio del Fonds Ricoeur y L'École des Hautes Études en Sciences Sociales. La organización estuvo a cargo de Olivier Abel, François Dosse, Catherine Goldenstein, Sabina Loriga y Jean-Marie Shaeffer.

Este Coloquio, además, marcó la apertura al público del Fonds Ricoeur, organismo encargado de preservar el legado de Ricoeur, sus publicaciones, sus textos inéditos, dar a conocer las publicaciones recientes en torno al autor, actualizar y difundir las investigaciones sobre su obra en todo el mundo a través de la página web, etc. El Fonds Ri- coeur se ubica a un costado de la Facultad de Teología Protestante y desde su apertura al público constituye un lugar de consulta obligado para los expertos e investigadores ricoeurianos.

Es importante destacar la preocupación de los organizadores por generar además, el día anterior al Coloquio, un espacio para la presentación de los distintos grupos de estudio en torno a Ricoeur, a fin de recoger la recepción de este autor en los distintos países de Europa, América Latina, Asia y los Estados Unidos.

Durante el Coloquio los ejes temáticos de las presentaciones pueden clasificarse en:

1. La recepción de $\mathrm{MHO}$ en el diálogo interdisciplinar $y / 0$ con otros autores Morny Joy, Jeanne-Marie Gagnebin, Christian Delacroix, Sabina Loriga, Myriam Revault d'Allonnes). 
Se trata de autores tales como W. Benjamin y Hannah Arendt; la recepción desde la historiografía; el diálogo con la literatura.

Respecto al diálogo con esta última se realiza una consideración en torno al tratamiento del tema de la memoria en las novelas y los relatos historiográficos, se destaca la figura del historiador en distintas novelas y cómo en ellas se pone en tela de juicio el discurso de los historiadores. Se ejercita la sospecha frente a los intentos de manipulación de la historia oficial. En MHO la sospecha recae sobre la memoria misma y se subraya la importancia de representar el pasado (Sabina Loriga). Además, la literatura permite recuperar la dimensión narrativa de la ética, que refunda la conciencia de las comunidades y puede llamar a la compasión (Myriam Revault d'Allonnes).

2. Aspectos especificos de la obra, sus vinculos con obras anteriores del autor y sus proyecciones (Frédéric Worms, Johann Michel, Jean-Michel Frodon, Olivier Abel, Philippe Joutard, Jean-Marie Schaeffer, Francois Hartog, François Dosse, Annete Wieviorka).

Se aborda el concepto de representancia, la cuestión de la historia, la cuestión del olvido. Se establecen ciertos vínculos con Vivo hasta la muerte y Tiempo y relato. Se percibe continuidad con conceptos forja- dos en estas obras precedentes y se realizan referencias en torno a la antropología subyacente, es decir, el hombre agente y sufriente que da origen a una ontología histórica, regional y fragmentada. Del mismo modo, se constata que el relato cruza toda la obra de Ricoeur, que va más allá de lo literario, ya que configura la identidad del sujeto puesto que el relato se constituye en nuestro modo particular de ser-en-el-mundo.

Respecto a la discontinuidad con otras obras que le anteceden: en Tiempo y relato se analizan cuestiones ligadas al estudio que Ricoeur realiza en torno al tipo de reconstrucción que ejecuta el historiógrafo. La función de la representancia implica reconstruir el pasado a través de huellas y vestigios. Desde aquí se funda una ontología histórica. Se borran las fronteras entre historia y ficción. En MHO se vuelve a tocar el tema de la representancia pero con otro tono, ya que acá se enfatiza una pulsión realista que no está en Tiempo y relato. Esto se explica por el énfasis dado al hecho histórico de la Shoah (Johann Michel), hay un nuevo contexto histórico que favorece el tono de una protesta moral.

El tema ético es replanteado desde la memoria en el sentido de el deber de la memoria que me obliga a descentrarme de mí mismo y 
ejercer la memoria solidaria con las víctimas.

Además se plantea el tema del olvido y la memoria, tanto individual como colectiva; el olvido y la memoria manipulada, entre otras formas de hacer memoria.

3. La recepción de $M H O$ en su aplicación a los diferentes contextos históricos (Francois Azouvi, Andris Breitling, Nikolay Koposov, Smaranda Vultur, Luba Jurgenson).

Se aborda en especial la Shoah, pero también otros contextos marcados por la violencia, tales como: el contexto ruso y rumano; la dictadura militar de Brasil y la situación de los detenidos desaparecidos, la negación de estas muertes y su persistencia en la memoria de los familiares de estas víctimas. Además se marca la diferencia entre la recepción de Tiempo y relato, junto a $S_{i}$ mismo como otro, que han tenido una buena acogida. Con MHO, en cambio, se abre una polémica. La recepción de MHO está marcada por la historia del reconocimiento del genocidio de los judíos (François Azouvi). Ricoeur se enfrenta al hecho del desafío para una filosofía de la historia de marcar la singularidad de la Shoah como acontecimiento único, incomparable y límite. En ese sentido, se habla de MHO como un «monumento de inquietud» (Olivier Abel).

Para ver el programa completo, audios y fotos del eventos, así como los discursos de apertura visitar: http://www.fondsricoeur.fr/ intro.php

Cristina Bustamante E. 